\title{
Replanteamiento de la Agenda 2030 ante el escenario de crisis pandémica: mirada desde la sociología*
}

\author{
Rethinking the 2030 Agenda in a pandemic \\ crisis scenario: a view from Sociology
}

\section{Rubén Tamboleo García* *}

Artículo de investigación

Fecha de recepción: 7 de junio de 2021

Fecha de aceptación: 22 de julio de 2021

\section{Para citar este artículo:}

Tamboleo García, R. (2021). Replanteamiento de la Agenda 2030 ante el escenario de crisis pandémica: mirada desde la sociología. Revista Análisis Jurídico-Político, 3(6), 75-96. https:// doi.org/10.22490/26655489.4805

\section{Resumen}

La pandemia de COVID-19 ha afectado de manera contundente tanto a países desarrollados como en vías de desarrollo. Las políticas públicas, planes de desarrollo y planes estratégicos, como

\footnotetext{
* Artículo de investigación en el marco académico de la Facultad de Ciencias Políticas y Sociología de la Universidad Complutense de Madrid.

* Máster en Gobierno y Administración Pública y Doctorando en Sociología (fase ABD) en la Universidad Complutense de Madrid. Profesor asociado de Sociología aplicada de la Universidad Complutense de Madrid. Autor de artículos indexados, libros y capítulos de libros con diferentes editoriales. Director de varias monografías en administración pública. Ha sido profesor visitante en el campus de Mahdía (Túnez), e investigador visitante en las universidades de Liverpool y Viena. Investigador de proyectos de innovación educativa, de proyectos I+D con empresas y de proyectos de investigación internacional como COST IS1308 y Horizon2020 "REMINDER". Secretario del comité científico del Congreso Internacional en "Gobernanza y Asuntos Públicos" en cuatro ediciones y "Desafíos Populistas". Profesor y director de cursos en comunicación política y en administración pública de la FGUCM 7 ediciones. Secretario académico en la “XII Aula de verano Ortega y Gasset" UIMP. Ponente en más de 40 congresos internacionales. Evaluador ACAP, ECREA, COST y revistas indexadas. Analista para diferentes medios (laSexta, RT, Telemadrid, $A B C$ ). Consultor en formación y asuntos públicos. Pozuelo de Alarcón, España. Correo electrónico: tamboleo@cps.ucm.es; ORCID: https://orcid.org/0000-0003-1631-0815
} 
la Agenda 2030, han quedado impactados considerablemente. La metodología de esta investigación consistió en examinar entre los países latinoamericanos, aquellos con mayor nivel de avance en la implementación de la Agenda 2030 y los que estaban con más retraso. Esto se estableció determinando cuáles países contaban con un departamento gubernamental para el desarrollo de la agenda; a partir de ello, se establecieron cuatro niveles. Aquellos países que no realizaron ningún avance, difícilmente podrían lograr la consecución de los ODS de manera efectiva para el año 2030. Además, el texto invita a la reflexión profesional, académica y científica al preguntar de qué manera - y de forma crítica- este escenario de crisis, en el que a la mayoría de países les va a costar despegar unos años, es compatible con el mantenimiento de la Agenda 2030 tal y como estaba prevista. Este planteamiento es igual de efectivo para países menos desarrollados o para aquellos con objetivos y prioridades que requieran mayor atención por parte de los Gobiernos e instituciones sociales. Por ello, si desde las más altas instancias se promueve la Agenda 2030 y los Objetivos de Desarrollo Sostenible (ODS), es importante abrir un espacio crítico para determinar si esto va a tener un efecto positivo en la sociedad latinoamericana o, por el contrario, tras el impacto de la crisis pandémica que no ha acabado, es necesario fijarse en otros objetivos. Como vemos, cabe un replanteamiento o una actualización de la agenda.

Palabras clave: políticas públicas, gobernanza, sociología política, sostenibilidad, totalitarismo, COVID-19, evaluación.

\section{Abstract}

The pandemic crisis has strongly affected both developing and developing countries, so that public policies, development plans and strategic plans such as the 2030 Agenda have been significantly impacted. As a methodology: examining the scope of Latin American countries, those that had been more involved, and those that were later, can be done by examining which ones had established a government department at the country level for the implementation of the agenda. Those who have not done so will be more difficult to join the achievement of the SDGs effectively by the year 2030. In addition, inviting professional, academic and scientific reflection, it is worth 
asking ourselves in what way, and critically, in this scenario of a crisis that indicates that in most countries, it will cost us to take off a few years, maintenance is compatible of the Agenda as planned, if this approach is equally effective for less developed countries, or if there are objectives and priorities that should now receive greater attention from governments and social institutions. Therefore, if the 2030 Agenda and the Sustainable Development Goals are promoted from the highest levels, it is important to be able to open a critical space to whether this is going to have a positive impact on Latin American society, or nevertheless after the impact of the Pandemic crisis that has not ended, it is necessary to set other objectives. As we can see, there is room for a rethinking or an update of the agenda.

Keywords: Public policies, governance, political sociology, sustainability, totalitarianism, COVID-19, evaluation.

\section{INTRODUCCIÓN}

Ante las diferentes propuestas de la Agenda 20301, cabe plantear una mirada crítica y propositiva. Hasta ahora se ha hecho hincapié en los posibles resultados positivos - especialmente en la opinión publicada—; sin embargo, no se ha puesto en cuestión su viabilidad después de la enorme crisis provocada por el impacto de la pandemia, que ha puesto en jaque y ha cambiado la vida de millones de personas en el mundo. Aunque sí ha habido algunas críticas desde algunos extremos del tablero político, como la posibilidad de que fuese una agenda excesivamente neoliberal (Medina, 2016), la aproximación general ha sido la de destacar las oportunidades y los factores positivos por parte de diferentes autores de distintas disciplinas y procedencias (Manero Salvador, 2018; Mariosa et ál., 2020; Rodríguez Valls, 2020).

Después del escaso éxito de los Objetivos de Desarrollo del Milenio (ODS) (Aguilar, 2016; El portal de noticias de Economía Circular, 2019) y el agotamiento de su marco temporal, se deseaba plantear un nuevo

1 La Agenda 2030 define los nuevos 17 Objetivos de Desarrollo Sostenible (ODS) y 169 metas, que sustituyen a los ocho Objetivos de Desarrollo del Milenio (ODM) establecidos por la comunidad internacional en el año 2000 y que terminaron en el año 2015 (Diario Responsable, 2015). 
enfoque mejorado de esta temática: una agenda de sustentabilidad a nivel global. Así, para interpretar los Objetivos de Desarrollo Sostenible (ODS) se deben de tener en cuenta los ODM como antecedentes políticos, sociales y económicos de la Agenda 2030. Este nuevo marco de trabajo de sustentabilidad se realiza de manera optimista, en la que se presuponía una cierta estabilidad en el horizonte, en especial de tipo económico, pero también de paz entre países y de asentamiento político. No se preveían escenarios que la impactan de forma severa, como la emergencia del populismo - con fuerza y capacidad de decisión política en determinados países- y en especial la pandemia derivada de la enfermedad ocasionada por el virus SARS-CoV-2, o COVID-19, que ha cambiado el mundo.

La pandemia ha producido un retroceso económico, social y, además, en las libertades individuales, como no se había conocido en el planeta desde el fin de la segunda guerra mundial en 1945 por causas políticas, y desde el final de la pandemia por la gripe de 1918, por causas sanitarias de una envergadura similar. Aunque sí hubo amenazas sanitarias, no llegaron a desarrollarse.

Este escenario de profundo cambio se debe examinar para determinar si es posible el mantenimiento de la Agenda 2030, con esa estructura y objetivos originales. Además de la limitación de la agenda, también se deben tener en cuenta los problemas, barreras y limitaciones de las agendas a largo plazo como efectos y elementos negativos de esta.

\section{Metodología}

Para la elaboración del presente trabajo se utilizaron fuentes secundarias. Limitamos los países de nuestra investigación al ámbito latinoamericano y examinamos un marco temporal limitado, que viene dado desde la aprobación de la Agenda 2030 en el año 2015, y especialmente los últimos 14 meses, hasta mayo de 2021, en el marco de la crisis y los cambios derivados por la pandemia que ha azotado todo el planeta. De esta manera, nos planteamos las siguientes preguntas de investigación:

- Pregunta de investigación 1: ¿pueden mantenerse las prioridades y los 17 ODS en el contexto de crisis pandémica? 
- Pregunta de investigación 2 (sujeta de manera secundaria a la primera): ¿es viable la Agenda 2030 después de la COVID-19?

Con esta metodología, se estableció un trabajo de inicio de investigación, que dejó un marco abierto y de referencia para ulteriores estudios sobre esta temática, que tendrán un impacto en áreas como la sociología política, las relaciones internacionales y la evaluación de políticas públicas.

\section{La Agenda 2030}

En primer lugar, se debe caracterizar esta agenda ${ }^{2}$ como una herramienta prospectiva. Esto quiere decir que tenemos que predecir un escenario, e intentar anticiparnos al mismo, según unos objetivos y unas metas deseadas en ese marco temporal, para entonces intentar conseguirlos con unas determinadas herramientas propuestas.

En segundo lugar, debemos entender la Agenda 2030 como un marco general para las políticas públicas. Esta afecta a gran parte - a la mayoría o casi a la totalidad- de las políticas públicas de los países que se han adherido a la agenda, en todos los niveles (nacional, regional y local). De igual manera, abarca también a diferentes sectores de política pública, cuyos desarrollos no pueden ser contrarios a dichas metas de la Agenda; o, al menos, debe fijarse en alguna de sus metas para intentar implementarla y que pueda tener un efecto significativo a través de las agencias de seguimiento estadísticas encargadas en cada uno de los países para transmitirle los datos a la ONU.

En tercer lugar, se examina cómo se ha desarrollado su marco político y organizativo en los países latinoamericanos, como se puede apreciar en la tabla 1. Aquí, se establecen cuatro niveles de importancia organizativa:

2 Podemos encontrar información detallada sobre la aprobación de la Agenda 2030 y sus características en el sitio web de la Organización de las Naciones Unidas. Algunos de estos aspectos se omiten aquí, porque no es objetivo de este trabajo desentrañar las particularidades de esta, y por razones de concisión y de posibilitar el debate académico en los aspectos que se recogen (sitio web: https://www.un.org/sustainabledevelopment/es/2015/09/la-asamblea-general-adopta-la-agenda-2030-para-el-desarrollo-sostenible/) 
1. Nivel 1: la Agenda 2030 se maneja políticamente en el país al más alto nivel, presidencia del ejecutivo.

2. Nivel 2: la Agenda 2030 se maneja políticamente a nivel ministerial o de secretaría, justo por debajo de la presidencia del país.

3. Nivel 3: la Agenda 2030 se maneja al menos en dos niveles por debajo del de la presidencia del ejecutivo del país, tales como viceministerio, vicesecretaría, vicecanciller o secretaría de Estado, o cuenta con un órgano especial y / o además cuenta con una secretaría general técnica.

4. Nivel 4: la Agenda 2030 se maneja en más de dos niveles por debajo de la presidencia del ejecutivo del país, o no existe una institucionalidad a nivel organizativo del poder ejecutivo del sistema político del país. Puede existir un seguimiento de indicadores estadísticos o un organismo de la ONU en el país que haga un seguimiento determinado.

Tabla 1. Importancia organizativa de la Agenda 2030 para los países latinoamericanos

\begin{tabular}{|c|c|c|c|}
\hline País & Institucionalidad & $\begin{array}{l}\text { Secretaría } \\
\text { técnica }\end{array}$ & Nivel \\
\hline $\begin{array}{l}\text { Antigua y } \\
\text { Barbuda }\end{array}$ & & & Nivel 4 \\
\hline Argentina & $\begin{array}{l}\text { Consejo Nacional de } \\
\text { Coordinación de las } \\
\text { Políticas Sociales de } \\
\text { La Argentina }\end{array}$ & & Nivel 3 \\
\hline Bahamas & $\begin{array}{l}\text { Unidad de Planificación y } \\
\text { Desarrollo Económico }\end{array}$ & & Nivel 3 \\
\hline Barbados & & & Nivel 4 \\
\hline Belice & $\begin{array}{l}\text { Ministerio de Desarrollo } \\
\text { Económico }\end{array}$ & & Nivel 2 \\
\hline $\begin{array}{l}\text { Estado } \\
\text { Plurinacional de } \\
\text { Bolivia }\end{array}$ & $\begin{array}{l}\text { Comité Interinstitucional } \\
\text { de las metas del PDES y } \\
\text { de Desarrollo Sostenible } \\
\text { (CIMPDS) de Bolivia }\end{array}$ & & Nivel 3 \\
\hline
\end{tabular}


Tabla 1. Importancia organizativa de la Agenda 2030 para los países latinoamericanos (continuación)

\begin{tabular}{|c|c|c|c|}
\hline País & Institucionalidad & $\begin{array}{l}\text { Secretaría } \\
\text { técnica }\end{array}$ & Nivel \\
\hline Brasil & $\begin{array}{l}\text { Secretaria de Governo da } \\
\text { Presidência da República } \\
\text { do Brasil }\end{array}$ & & Nivel 2 \\
\hline Chile & $\begin{array}{l}\text { Consejo Nacional para } \\
\text { la implementación de } \\
\text { la Agenda } 2030 \text { para el } \\
\text { Desarrollo Sostenible de } \\
\text { Chile }\end{array}$ & $\begin{array}{l}\text { Ministerio de } \\
\text { Desarrollo } \\
\text { Social de Chile }\end{array}$ & Nivel 2 \\
\hline Colombia & $\begin{array}{l}\text { Comisión interinstitucional } \\
\text { de alto nivel para el } \\
\text { alistamiento y la efectiva } \\
\text { implementación de la } \\
\text { Agenda } 2030\end{array}$ & $\begin{array}{l}\text { Departamento } \\
\text { Nacional de } \\
\text { Planeación } \\
\text { (DNP) de } \\
\text { Colombia }\end{array}$ & Nivel 3 \\
\hline Costa Rica & $\begin{array}{l}\text { Consejo de alto nivel } \\
\text { de los Objetivos de } \\
\text { Desarrollo Sostenible }\end{array}$ & $\begin{array}{l}\text { Ministerio de } \\
\text { Planificación } \\
\text { y Política } \\
\text { Económica } \\
\text { (Mideplan) }\end{array}$ & Nivel 2 \\
\hline Cuba & $\begin{array}{l}\text { Grupo Nacional (GN) para } \\
\text { la implementación de } \\
\text { la Agenda } 2030 \text { para el } \\
\text { Desarrollo Sostenible }\end{array}$ & & Nivel 3 \\
\hline Dominica & $\begin{array}{l}\text { Ministerio de Planificación } \\
\text { y Desarrollo Económico }\end{array}$ & & Nivel 2 \\
\hline Ecuador & Planifica Ecuador & & Nivel 3 \\
\hline EI Salvador & $\begin{array}{l}\text { Consejo Nacional de } \\
\text { Desarrollo Sostenible de } \\
\text { El Salvador }\end{array}$ & & Nivel 3 \\
\hline Granada & & & Nivel 4 \\
\hline Guatemala & $\begin{array}{l}\text { Consejo Nacional de } \\
\text { Desarrollo Urbano y Rural } \\
\text { (Conadur) }\end{array}$ & $\begin{array}{l}\text { Secretaría de } \\
\text { Planificación y } \\
\text { de Programación } \\
\text { de la } \\
\text { Presidencia } \\
\text { (Segeplan) }\end{array}$ & Nivel 3 \\
\hline Guyana & Ministerio de Finanzas & & Nivel 2 \\
\hline
\end{tabular}




\section{ANÁLISIS

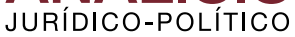

Tabla 1. Importancia organizativa de la Agenda 2030 para los países latinoamericanos (continuación)

\begin{tabular}{|c|c|c|c|}
\hline País & Institucionalidad & $\begin{array}{l}\text { Secretaría } \\
\text { técnica }\end{array}$ & Nivel \\
\hline Haití & $\begin{array}{l}\text { Ministerio de Planificación } \\
\text { y Cooperación Externa } \\
\text { (MPCE) }\end{array}$ & & Nivel 2 \\
\hline Honduras & $\begin{array}{l}\text { Comisión Nacional de la } \\
\text { Agenda } 2030 \text { para los } \\
\text { Objetivos de Desarrollo } \\
\text { Sostenible (CN-ODS) }\end{array}$ & $\begin{array}{l}\text { Secretaría de } \\
\text { Coordinación } \\
\text { General de } \\
\text { Gobierno }\end{array}$ & Nivel 1 \\
\hline Jamaica & $\begin{array}{l}\text { Comité Nacional de } \\
\text { Supervisión de la Agenda } \\
2030\end{array}$ & $\begin{array}{l}\text { Instituto de } \\
\text { Planificación de } \\
\text { Jamaica (PIOJ) }\end{array}$ & Nivel 3 \\
\hline España & $\begin{array}{l}\text { Ministerio de Derechos } \\
\text { Sociales y Agenda } 2030\end{array}$ & & Nivel 2 \\
\hline $\begin{array}{l}\text { Estados Unidos } \\
\text { Mexicanos }\end{array}$ & $\begin{array}{l}\text { Consejo Nacional de la } \\
\text { Agenda } 2030 \text { para el } \\
\text { Desarrollo Sostenible de } \\
\text { México }\end{array}$ & $\begin{array}{l}\text { Presidencia } \\
\text { de los Estados } \\
\text { Unidos } \\
\text { Mexicanos }\end{array}$ & Nivel 1 \\
\hline Nicaragua & & & Nivel 4 \\
\hline Panamá & $\begin{array}{l}\text { Comisión } \\
\text { Interinstitucional y de la } \\
\text { Sociedad Civil }\end{array}$ & $\begin{array}{l}\text { Ministerio de } \\
\text { Desarrollo } \\
\text { Social (MDS) }\end{array}$ & Nivel 2 \\
\hline Paraguay & $\begin{array}{l}\text { Comisión } \\
\text { Interinstitucional de } \\
\text { Coordinación para } \\
\text { la implementación, } \\
\text { seguimiento y monitoreo } \\
\text { de los compromisos } \\
\text { internacionales en el } \\
\text { marco de los ODS }\end{array}$ & $\begin{array}{l}\text { Ministerio de } \\
\text { Relaciones } \\
\text { Exteriores }\end{array}$ & Nivel 2 \\
\hline Perú & $\begin{array}{l}\text { Centro Nacional de } \\
\text { Planeamiento Estratégico }\end{array}$ & & Nivel 3 \\
\hline $\begin{array}{l}\text { República Domini- } \\
\text { cana }\end{array}$ & $\begin{array}{l}\text { Comisión } \\
\text { Interinstitucional de Alto } \\
\text { Nivel Político para el } \\
\text { Desarrollo Sostenible }\end{array}$ & $\begin{array}{l}\text { Ministerio de } \\
\text { Economía, } \\
\text { Planificación } \\
\text { y Desarrollo } \\
\text { (MEPyD) }\end{array}$ & Nivel 2 \\
\hline $\begin{array}{l}\text { San Cristóbal y } \\
\text { Nieves }\end{array}$ & & & Nivel 4 \\
\hline
\end{tabular}


Tabla 1. Importancia organizativa de la Agenda 2030 para los países latinoamericanos (continuación)

\begin{tabular}{|c|c|c|c|}
\hline País & Institucionalidad & $\begin{array}{l}\text { Secretaría } \\
\text { técnica }\end{array}$ & Nivel \\
\hline $\begin{array}{l}\text { San Vicente y las } \\
\text { Granadinas }\end{array}$ & & & Nivel 4 \\
\hline Santa Lucía & $\begin{array}{l}\text { Mecanismo nacional } \\
\text { de coordinación para la } \\
\text { implementación de la } \\
\text { Agenda } 2030 \text { y los } 17 \text { ODS }\end{array}$ & & Nivel 3 \\
\hline Surinam & & & Nivel 4 \\
\hline Trinidad y Tobago & $\begin{array}{l}\text { Subcomité ministerial de } \\
\text { alto nivel del gabinete } \\
\text { sobre la visión } 2030 \text { y los } \\
\text { ODS de Trinidad y Tobago }\end{array}$ & $\begin{array}{l}\text { Ministerio de } \\
\text { Planificación } \\
\text { y Desarrollo } \\
\text { (MPD) }\end{array}$ & Nivel 2 \\
\hline Uruguay & $\begin{array}{l}\text { Oficina de Planeamiento y } \\
\text { Presupuesto (OPP) }\end{array}$ & & Nivel 3 \\
\hline $\begin{array}{l}\text { República } \\
\text { Bolivariana de } \\
\text { Venezuela }\end{array}$ & $\begin{array}{l}\text { Consejo de Vicepresiden- } \\
\text { tes de Venezuela }\end{array}$ & $\begin{array}{l}\text { Vicepresidente } \\
\text { ejecutivo de la } \\
\text { República de } \\
\text { Venezuela }\end{array}$ & Nivel 2 \\
\hline
\end{tabular}

Fuente: elaboración propia con base en Agenda 2030 en América Latina y el Caribe, Plataforma Regional de Conocimiento (2020).

Se encontraron: 2 países en nivel 1, 13 países en nivel 2, 12 países en nivel 3 y 7 países en nivel 4 . Se destacan como los más importantes los niveles 1 y 2 . Los países clasificados en el nivel 4 se consideran con muy bajo compromiso y poca acción para el desarrollo de la Agenda 2030. Teniendo en cuenta que se examinó un total de 34 países, el $20.59 \%$ de estos no ha empezado a implementar la Agenda 2030 con un soporte organizativo y político.

\section{Otras agendas: España 2050}

Se puede apreciar cómo algunos países se han sumado a la dinámica de establecer agendas prospectivas, aunque estas no sean solo de sostenibilidad, sino, en general, agendas de desarrollo que permitan examinar qué modelo se quiere en un lapso determinado. 
Así, España ha planteado la Agenda 2050, que pretende un proyecto colectivo para decidir "qué país queremos ser dentro de 30 años" (Presidencia del Gobierno de España, 2021). Ante este tipo de planteamientos, lo que se pregunta una parte de la sociedad, como lo ha hecho la escritora Ana Iris Simón, es:

[...] está muy bien ayudar a empresas ecológicas y ponerle wifis al campo. Pero no habrá Agenda 2030 ni plan 2050 si en 2021 no hay techo para las placas solares, porque no tenemos casas, ni niños que se conecten al wifi porque no tenemos hijos. (Periódico El Mundo, 2021)

Esto constituye una crítica a este tipo de agendas y una necesidad de planes urgentes para los problemas más acuciantes que afectan de manera distinta a las diferentes generaciones.

\section{Las ambiciones positivas de LA Agenda 2030}

Un aspecto positivo es que, frente a las ODM, se intenta apuntar, al menos, a 169 metas distribuidas entre los 17 ODS. Con ello, se puede hacer un diagnóstico de la evolución de cada una de las metas y examinar si se han producido mejoras o empeoramientos. Se ha creado una moda con capacidad de influencia en la sociedad, tal y como lo hemos visto con la Agenda 2050 para el caso de España. Asimismo, se involucra a más países que en intentos anteriores, dándoles la oportunidad de acceder a más tipos de recursos, y que confluyan países en vías de desarrollo, con aquellos plenamente desarrollados. Además, se plantea, con una ambición mucho mayor que en casos anteriores, que los ODS (tanto en su cantidad como en el intento de profundización cualitativo) tengan un componente de transformación general y una potencialidad de cambio global, para conseguir todo un nuevo modelo a largo plazo.

\section{LoS MARCOS NEGATIVOS DE LAS AGENDAS PROSPECTIVAS, especialmente de la Agenda 2030}

Las agendas prospectivas plantean una serie de elementos negativos para el sistema político de un país y para la propia sociedad. De 
estos se destacan algunos, teniendo en cuenta el mayor impacto y profundidad: los ciclos políticos y electorales, la capacidad de deliberación, la amenaza totalitarista o totalitaria, el factor generacional y los cambios de escenario.

\subsection{Los CICLOS POLÍtiCOS Y ELECTORALES}

Los ciclos políticos y electorales de cada país plantean dos barreras de especial importancia. A saber:

1. Si a unos determinados años vista, se decide hacer toda una serie de planes, esos planes hurtarían la capacidad de decisión de los representantes electos para los siguientes años. Por lo tanto, cabe preguntarse: ¿qué legitimidad o capacidad tienen los representantes elegidos para 2, 3, 4 o 5 años de firmar o de comprometerse con planes que vayan a durar 10, 15 o más años? Si se limita esa capacidad de decisión, estaríamos hablando de que ese nivel de decisión tendría que enmarcarse en el nivel constitucional de cada país (introduciendo reformas limitantes dentro de cada constitución).

2. Si se eligen unos representantes con una visión bien diferente en los aspectos que abarcan esta agenda, no mantendrán los compromisos, y girarán la acción política hacia otro tipo de direcciones y objetivos diferentes. El planteamiento por marcos temporales tan largos puede también restar su eficacia y su capacidad de implementación de manera acorde con los resultados que se puedan contrastar. Un ejemplo claro de esto es la elección de Jair Bolsonaro (Castro Vizentín, 2019).

\subsection{LA CAPACIDAD DE DELIBERACIÓN}

Tanto lo que entendemos como procesos deliberativos de democracias constitucionales avanzadas con procesos de innovación democrática (Geissel y Gherghina, 2016), como los procesos de gobernanza (Bañón i Martínez y Tamboleo García, 2015) requieren redes de permeabilidad, en las que la ciudadanía puede participar, especialmente en el diseño, implementación y evaluación de políticas públicas.

Restringir los marcos de deliberación, de innovación y de las redes de gobernanza, como lo hacen los 17 ODS, resulta en un perjuicio para 
todo este tipo de procesos y para el acercamiento de la ciudadanía al gobierno y a la administración pública general. Esto da una percepción de que ya todas las cartas están marcadas, y de que existen otros posibles tipos de riesgos, como la confusión de lo que está permitido y lo que no. Por ejemplo, dentro de los 17 ODS se intenta implementar el uso del coche eléctrico, pero determinados colectivos de ecologistas pregonan que la extracción de litio —el componente básico de las baterías (figura 1) — es peligrosa y puede ser perjudicial para el medio ambiente. Esto se evidenció en las protestas por una mina de litio en la región española de Extremadura: por un lado se decía que España tiene la segunda mina de litio más grande de Europa, en la que los responsables del proyecto calculaban que tiene capacidad para abastecer hasta 10 millones de coches eléctricos, con el aval de la Unión Europea (López Redondo, 2020), mientras que por otro ha recibido movilizaciones para la paralización definitiva de la extracción (Méndez, 2021).

Figura 1. Millones de toneladas de necesidad de litio estimadas

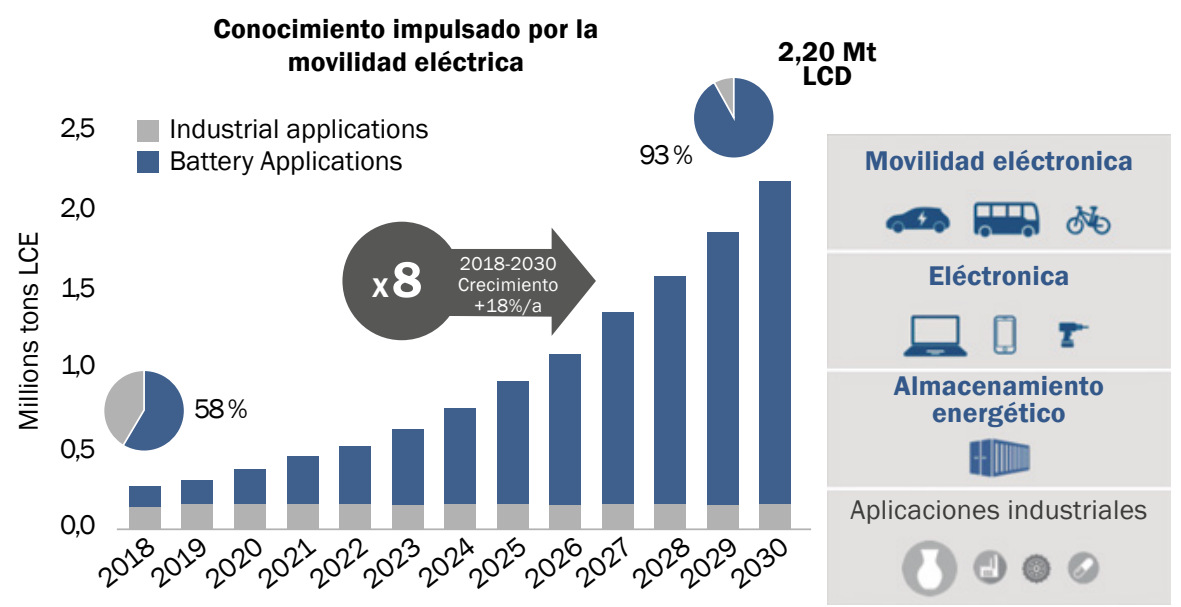

Fuente: Canaccord Genuity (2019).

3 Además, esta mina de litio sería clave para el impulso industrial de esta zona deprimida, pudiendo atraer fábricas de baterías a la zona, que realizarían todo el proceso allí, evitando costes logísticos y medioambientales (Semprún y Ferrari, 2019). 
Además de limitar la deliberación y los procesos de gobernanza, que requieren planteamientos mucho más abiertos, puede generar desconfianza en la ciudadanía: ¿dónde están los límites y hasta dónde se debe de llegar? Es decir, ¿cuánto va a tener que sacrificar la persona común en su calidad de vida, para poder garantizar un futuro sustentable? También, ¿qué capacidad de crítica se puede tener ante este tipo de marco general de políticas?, el cual, como veremos en el siguiente apartado, pretender abarcar de forma completa la vida de una persona, teniendo también en cuenta otros peligros o dificultades en este sentido, como posibles caídas en el relativismo de la democracia (Ruiz Miguel, 2019).

\subsection{LA AMENAZA TOTALITARISTA O TOTALITARIA}

El totalitarismo es entendido como aquellas formas de acción política en la que un Estado o varios Estados pretender dirigir completamente todos los aspectos de la vida de una persona, limitando su libertad y su capacidad de acción. Lo anterior tiene como referencia conceptual la obra de Hannah Arendt (1951) "Los orígenes del totalitarismo". De esta manera, se aprecia como con la Agenda 2030 se le está pidiendo a la población, de manera muy notable, cambios en las formas de vida y en sus hábitos de consumo. Con ello se intenta delimitar que hay ciudadanos con mayor conciencia social o que son mejores que otros en función de cómo viajen, cómo vistan, su medio de transporte habitual, su dieta u otras visiones de la vida en sociedad, cómo se comportan.

En este sentido, tenemos varios ejemplos como: "reducir el consumo de carne para salvar el planeta" (Caja de Ingenieros, 2020), limitar los viajes en avión (incluso plantean que dejáramos de volar durante un determinado tiempo para salvar el mundo) (Sader, 2018) o dejar de comprar un determinado tipo de ropa o hacerlo de forma mucho más limitada, porque dicen que "la industria de la moda emite el $10 \%$ del carbono, es el segundo mayor consumidor de agua en el mundo y contamina los océanos con microplásticos" (Castañeda, 2020). Si se sigue este camino de limitación de la libertad individual, ¿dónde está el límite? 


\subsection{EL FACTOR GENERACIONAL}

Las agendas prospectivas no afectan por igual las distintas generaciones, las cuales ya de por sí ni siquiera tienen las mismas características. Podemos plantear de forma básica tres cuestiones: la propia evolución demográfica, la incorporación progresiva a la ciudadanía de nuevos ciudadanos, y las problemáticas que afectan de manera no uniforme a las distintas generaciones.

En cuanto a la primera cuestión, se plantea el derecho a la reproducción en libertad de la raza humana, porque según la propia $\mathrm{ONU}$, "el fuerte crecimiento poblacional supondrá un reto para lograr un desarrollo sostenible" (Organización de Naciones Unidas [ONU], Departamento de Asuntos Económicos y Sociales, 2019). De esta manera se está limitando el derecho a formar familias o se abre el planteamiento para esta limitación.

Con la Agenda 2030 se plantean unos objetivos en un marco temporal de 15 años, que afectaría a dos nuevas generaciones que se van incorporando a la ciudadanía a lo largo de ese lapso.

En cuanto a la tercera cuestión, vemos que problemáticas como la educación y el empleo afectan de forma desigual a los distintos grupos eterios. Por ejemplo, el paro en determinados lugares y sectores se ceba de manera férrea con unas generaciones u otras según las circunstancias. Ejemplo de ello es la crisis pandémica en España, que con los españoles de 35 a 44 años tiene un impacto más profundo, con 210528 empleos destruidos entre marzo de 2020 y mayo de 2021, en los que las afiliaciones a la seguridad social se desplomaron en ese grupo de edad, entre otras razones, por el menor coste de la rescisión de los contratos (Martín, 2021).

\subsection{LOS CAMBIOS DE ESCENARIO}

Sobre la problemática de los cambios de escenario, en el siguiente apartado nos centramos especialmente en el cambio de condiciones más grande que hemos tenido. Pero sin tener uno tan dramático, puede haber cambios de escenario medianos o pequeños, que limiten la capacidad de estas agendas. Esto hace que se deba tener en cuenta también las particularidades de los escenarios locales y nacionales frente a este enfoque globalista. 
Además, se deben poder contemplar otros aspectos, por ejemplo que los ODS puedan introducir factores limitantes a países que están en vías de desarrollo, o con umbrales que dejan a la mayoría de la población a merced de la pobreza. Esos factores, se explican a la luz de que, por ejemplo, los países que ahora están en su máximo nivel de desarrollo lo han alcanzado sin limitarse en cuánto y cómo accedían a los recursos naturales; $\mathrm{y}$ ahora se pide a aquellos que están en vías de desarrollo, o en condiciones aún más precarias, que se limiten y que se acojan a determinados políticas de sustentabilidad, que pueden cronificar su mala situación económica y de desarrollo social.

\section{El CaMbio en los países latinoamericanos de LA CRISIS PANDÉMICA}

El impacto de la crisis pandémica ha sido muy alto y va más allá de lo económico. Afecta a la libertad, el desarrollo personal y la calidad de vida, o, al movimiento de las personas: el volumen total de pasajeros en 2020 se redujo un 60 \% (Organización de Aviación Civil Internacional -OACI-, 2021). En ese contexto, analizaremos cuáles han sido los países latinoamericanos más impactados, con el propósito de evidenciar la desigualdad con las cifras de casos por millón de personas. Se seleccionaron los ocho países con mayor número de casos (tabla 2) y la desigualdad ya existente en términos de Producto Interno Bruto (IBP) per cápita en Paridad de Poder Adquisitivo (PPA) (tabla 3).

Tabla 2. Los ocho países latinoamericanos con mayor número de casos

\begin{tabular}{|c|c|c|c|c|}
\hline País & $\begin{array}{l}\text { Total de } \\
\text { casos }\end{array}$ & $\begin{array}{l}\text { Casos nuevos } \\
\text { (1 día) }\end{array}$ & $\begin{array}{l}\text { Casos por } 1 \text { millón } \\
\text { de personas }\end{array}$ & Fallecidos \\
\hline Brasil & 16907425 & 66017 & 80002 & 472531 \\
\hline España & 3697981 & 0 & 78513 & 80196 \\
\hline
\end{tabular}




\section{ANÁLISIS

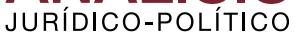

Tabla 2. Los ocho países latinoamericanos con mayor número de casos

(continuación)

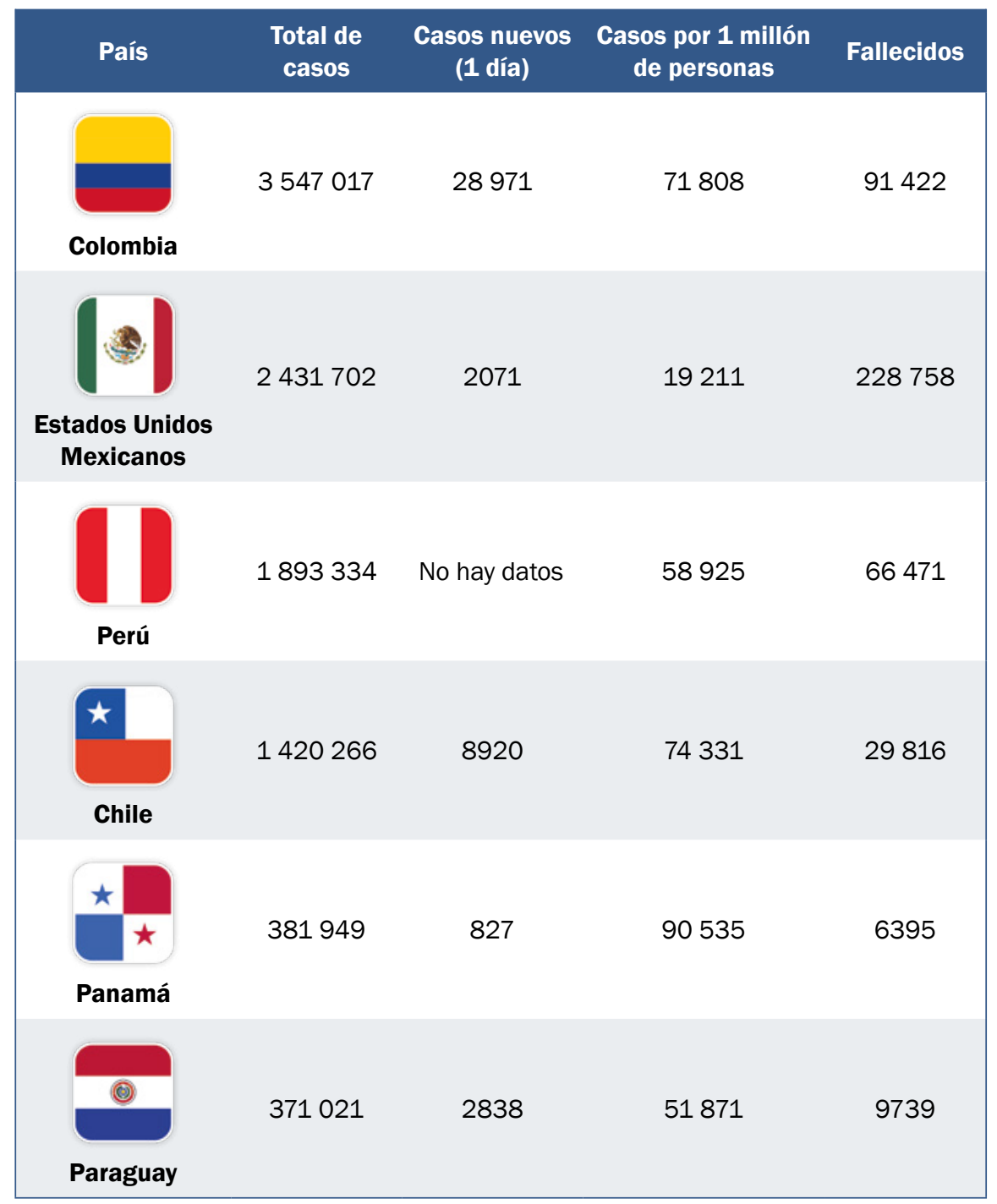

Fuente: Google noticias (2021).

También de manera crítica y al margen del cambio del escenario, es necesario entender que los países latinoamericanos tienen niveles de desarrollo político, social y económico, y de calidad de vida bien diferenciados. Esto se expresa mediante diferentes indicadores, y para el presente trabajo nos fijamos en el PIB per cápita en términos de PPA. 
Tabla 3. Posición de los países latinoamericanos por renta per cápita

\begin{tabular}{|c|c|c|c|}
\hline $\begin{array}{l}\text { Posición en } \\
\text { el mundo }\end{array}$ & País & $\begin{array}{c}\text { Dólares } \\
\text { internacionales }\end{array}$ & Año \\
\hline 32 & España & 30600 & 2011 \\
\hline 47 & * Antigua y Barbuda & 22100 & 2011 \\
\hline 48 & Trinidad y Tobago & 20300 & 2011 \\
\hline 55 & Argentina & 17700 & 2011 \\
\hline 56 & Chile & 17400 & 2011 \\
\hline 58 & .7 San Cristóbal y Nieves & 16400 & 2011 \\
\hline 64 & 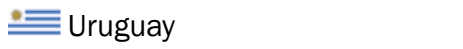 & 15400 & 2011 \\
\hline 65 & Estados Unidos Mexicanos & 15100 & 2011 \\
\hline 70 & $="=$ Dominica & 13600 & 2011 \\
\hline 71 & * Panamá & 13600 & 2011 \\
\hline 73 & $\square$ Granada & 13300 & 2011 \\
\hline 75 & A Santa Lucía & 12900 & 2011 \\
\hline 76 & Venezuela & 12400 & 2011 \\
\hline- & Mundo & 11800 & 2011 \\
\hline 79 & Iv San Vicente y las Granadinas & 11700 & 2011 \\
\hline 80 & 2. Brasil & 11600 & 2011 \\
\hline 81 & ㄷosta Rica & 11500 & 2011 \\
\hline 87 & Colombia & 10100 & 2011 \\
\hline 88 & Perú & 10000 & 2011 \\
\hline 89 & $\equiv$ Cuba & 9900 & 2010 \\
\hline 93 & 틈를 República Dominicana & 9300 & 2011 \\
\hline 94 & Jamaica & 9000 & 2011 \\
\hline 97 & 으 Belice & 8300 & 2011 \\
\hline 98 & Ecuador & 8300 & 2011 \\
\hline
\end{tabular}


Tabla 3. Posición de los países latinoamericanos por renta per cápita (continuación)

\begin{tabular}{|cccc|}
$\begin{array}{c}\text { Posición en } \\
\text { el mundo }\end{array}$ & País & $\begin{array}{c}\text { Dólares } \\
\text { internacionales }\end{array}$ & Año \\
\hline 102 & El Salvador & 7600 & 2011 \\
117 & Paraguay & 5500 & 2011 \\
123 & Guatemala & 5000 & 2011 \\
126 & Estado Plurinacional de Bolivia & 4800 & 2011 \\
131 & Hicaragua & 4300 & 2011 \\
141 & Haití & 3200 & 2011 \\
177 & & 1200 & 2011 \\
\hline
\end{tabular}

Fuente: Agencia Central de Inteligencia (CIA) de Estados Unidos de América del Norte (2017).

Para el cambio de escenario, se observa como la crisis ha tenido una especial dureza en Latinoamérica. La pandemia de COVID-19 ha saldado una caída del $8.1 \%$ del PIB en América Latina, superando el impacto de la crisis en la Unión Europea y de otras economías emergentes similares. Se estima que alrededor de tres millones de empresas de la región cerrarán y el número de pobres aumentará en casi 29 millones de personas (Sánchez Díez y Manuel, 2021). En este sentido, otros autores indican que los efectos de la pandemia a raíz de la propagación de la COVID-19 han develado el rostro sufriente de millones de seres humanos sobre el planeta y de manera cruel en América Latina, donde los Estados se han visto desbordados ante la magnitud de los contagios y los fallecimientos, el desempleo creciente y la escasez de recursos (Liñan Cuello et ál., 2021, p. 394).

\section{Conclusiones y discusión}

El artículo examina la Agenda 2030 como herramienta general, sin ahondar en cada una de las metas de los 17 ODS. Esto permite responder a las preguntas de investigación que nos hemos planteado, a través de las cuestiones que se han desarrollado. 
Sobre si se pueden mantener las prioridades y los 17 ODS en el contexto de crisis pandémica, hemos visto como el impacto es desigual; por ejemplo a través del número de casos por millón de habitantes, se evidencia que cada país necesita caminos distintos para poder rebajar los impactos negativos de la crisis económica.

Además, se ven cuestiones que son ajenas a la crisis pandémica y que se pueden aplicar a diferentes tipos de agendas prospectivas, pero que, sin embargo, están también relacionadas con los factores de la crisis creada con la COVID-19. Precisamente la conjunción o convergencia de estos factores negativos generales con los de la crisis pandémica, hacen que, de manera global, se haga aún más difícil mantener estas prioridades. También hay que tener en cuenta que con el cambio de escenario, dentro de los 17 ODS y sus respectivas metas, el peso de uno y de otros ha cambiado; por ejemplo, algunos, como los objetivos 1 y 2 , no pobreza y cero hambre, respectivamente, cobran aún mayor importancia.

También se evidenció que el nivel organizativo a escala políticaadministrativa en los países latinoamericanos es asimétrico. Esto hace presuponer resultados diferentes, puesto que, en nuestra clasificación de cuatro niveles, los 34 países han tomado decisiones de organización bien diferenciadas. También el impacto de casos de COVID-19 por millón de habitantes ha sido distinto en los países de Latinoamérica. Se constata que, como zona geográfica y política del mundo, la economía se ha llevado un especial impacto negativo. Así, la viabilidad y el futuro de esta agenda en la zona se hace más difícil, siendo aún más necesario un replanteamiento con otros objetivos y actuaciones urgentes.

De esta manera, sobre si es viable la Agenda 2030 después de la COVID-19, se observa que su posibilidad se ha visto seriamente perjudicada, y que el marco temporal 2030 para los objetivos propuestos se queda insuficiente, además de las otras barreras aquí recogidas como efectos negativos, que deben de tenerse en cuenta. Por el contrario, la viabilidad de una mayoría de metas es posible, puesto que su planteamiento se realiza de una forma muy general, con pocas especificidades y con una dificultad de evaluación y de comparación según los datos que se puedan recoger entre los diferentes países.

Por lo tanto, se hace necesario ahondar en la realidad de cada país, donde hay diferencias muy notables en indicadores de calidad de 
vida, como el PIB per cápita, como lo hemos visto, al margen de otros datos estructurales como su tamaño, población, desarrollo, entre otros.

Como discusión, para la comunidad científica, académica y profesional que ha trabajado la materia, lo que planteamos a partir de los resultados de la investigación es si la Agenda 2030 es una herramienta de estrategia y de prospectiva que puede generar resultados reales y contrastables, o si, por el contrario, nos encontramos con una herramienta que fomenta un tipo de propaganda, para expiar efectos negativos de algunos de sus actores políticos. Con todo, dejamos la discusión abierta para lo que sería el replanteamiento de la Agenda 2030, teniendo especial importancia el impacto de la crisis pandémica, que se puede desarrollar con ulteriores investigaciones, más aún cuando haya acabado la actual crisis sanitaria, que permita vislumbrar el final de la crisis económica y social.

\section{REFERENCIAS}

Agencia Central de Inteligencia (CIA) de Estados Unidos de América del Norte. (2017). Central de Inteligencia (CIA). https: / / bit.ly / 3x0NJyP

Agenda 2030 en América Latina y el Caribe, Plataforma Regional de Conocimiento.

(2020). Países: Informes nacionales voluntarios, mecanismos institucionales nacionales de coordinación y seguimiento para la implementación de la Agenda 2030 en los países de América Latina y el Caribe. https: / / bit.ly/3hWH30q

Aguilar, A. (2016, 20 de octubre). ¿Por qué fracasaron los Objetivos del Milenio? Expok Comunicación de Sustentabilidad y RSE. https: / / bit.ly / 3eRWF3f

Arendt, H. (1951). Los orígenes del totalitarismo (vol. 3). Taurus.

Bañón i Martínez, R. y Tamboleo García, R. (2015). Ideas para la Gobernanza. Editorial Fragua.

Caja de Ingenieros. (2020, 9 de abril). Reducir el consumo de carne, clave para salvar el planeta. ¿Qué relación hay entre reducir el consumo de carne y proteger el medio ambiente? El blog de Caja de Ingenieros. https: / / bit.ly / 3eSb1Rn

Canaccord Genuity. (2019). Canaccord Genuity - Lithium 2019 recharge. Obtenido de Canaccord Genuity.

Castañeda, J. (2020, 30 de septiembre). La industria de la moda emite el 10 por ciento de carbono, es el segundo mayor consumidor de agua en el mundo y contamina los océanos con microplásticos. El diario de finanzas. https: / / bit. ly $/ 3 \times 2 \operatorname{lmQE}$

Castro Vizentín, M. (2019, 25 de abril). El estreno de Bolsonaro amenaza el compromiso de Brasil con la Agenda 2030. Equal Times. https: / / bit.ly / 3hYJIGL 
Diario Responsable. (2015, 26 de septiembre). Aspectos positivos y negativos de la Agenda 2030, según Manos Unidas. https: / / bit.ly/3i0CaDF

El Mundo. (2021, 22 de mayo). Duro ataque de la escritora Ana Iris Simón a Sánchez: "No habrá España 2050 sin familias". https: / / bit.ly/3x1Hwm8

El portal de noticias de Economía Circular. (2019, 13 de agosto). DE LOS O.D.M. (FRACASO) A LOS O.D.S. (¿SEGUNDO FRACASO?). https:/ / bit.ly / 3ruNZ89

Geissel, B. y Gherghina, S. (2016). Constitutional deliberative democracy and democratic innovations. En M. Reuchamps (ed.), Constitutional Deliberative Democracy in Europe. Series: Studies in European political science (pp. 75-92.). ECPR Press.

Google noticias. (2021, 02 de junio). Coronavirus COVID 19 en el mundo. https: / / bit. ly/3kUjIyf

Liñan Cuello, Y. I., Mejía González, L. P. y Ospino Jaraba, D. E. (2021). La Agenda 2030: los desafíos al Estado y a la democracia. Revista de Filosofía / Centro de Estudios Filosóficos / Universidad del Zulia - Venezuela, 38(97), 383-394. https: / / doi.org/10.5281/ zenodo.4885116

López Redondo, N. (2020, 14 de enero). España tiene la segunda mina de litio más grande de Europa. Movilidad Eléctrica. https: / / bit.ly / 2TCiHzO

Manero Salvador, A. (2018). La protección ambiental del Ártico y la Agenda 2030. Actualidad Jurídica Ambiental, 77, 4-34. https: / / bit.ly /3BKdI1h

Mariosa, D. F., Benedicto, S. C., Georges, M. R. y Sugahara, C. R. (2020). A Agenda 2030 e o saneamento como indicador de sustentabilidade. Revista Cerrados, 18(01), 278-299. https: / / doi.org/10.46551/rc24482692202002

Martín, J. (2021, 06 de junio). La crisis se ceba con los españoles de 35 a 44 años: 210.528 empleos destruidos. Voz Pópuli. https: / / bit.ly/3eQMb4e

Medina, J. (2016). ¿Es la agenda 2030 una agenda neoliberal? Dossieres EsF, 22(verano 2016), 7-9.

Méndez, A. (2021, 11 de febrero). La Plataforma escenifica una protesta contra la mina de litio. Diario HOY de Extremadura. https: / / bit.ly / 3y12Qd2

Organización de Aviación Civil Internacional (OACI). (2021, 21 de enero). El volumen total de pasajeros en 2020 se redujo un $60 \%$ y el asalto de la COVID-19 a la movilidad internacional no se detiene. https:/ / bit.ly/3eSm4Km

Organización de Naciones Unidas, Departamento de Asuntos Económicos y Sociales. (2019, 1 de abril). El fuerte crecimiento poblacional supondrá un reto para lograr un desarrollo sostenible. Noticias ONU. https:/ / bit.ly/3i31bOB

Presidencia del Gobierno de España. (2021, 20 de mayo). Sánchez presenta 'España 2050 ', un proyecto colectivo para decidir "qué país queremos ser dentro de 30 años". Palacio de la Moncloa. https: / / bit.ly / 3iGtYaP

Rodríguez Valls, N. (2020). La Agenda 2030: una oportunidad para transformar la escuela. Cuadernos de pedagogía, 508, 64-69.

Ruiz Miguel, A. (2019). Agenda 2030, democracia y relativismo. En S. A. Margarita Alfaro (ed. lit.), Agenda 2030: Claves para la transformación sostenible (pp. 39-57). Los libros de la Catarata. 


\section{ANÁLISIS

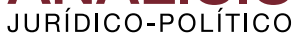

Sader, M. (2018, 20 de diciembre). ¿Dejarías de volar durante un año para salvar el mundo? Si no te montas en un avión en 2019, podrás disfrutar de viajar durante el resto de tu vida... Revista Traveler. https: / / bit.ly / 2Ty8mF1

Sánchez Díez, Á. y Manuel, G. d. (2021, 1 de marzo). Coronavirus en América Latina: las cifras que muestran el brutal impacto de la pandemia en las economías de la región. $B B C$ News. https: / / bbc.in/36TpMyW

Semprún, Á. y Ferrari, J. (2019, 30 de diciembre). La mina de litio de Extremadura, la clave para atraer fábricas de baterías. El Economista. https:/ / bit.ly/3y2dsbw 